\title{
small
}

Supporting Information

for Small, DOI: 10.1002/smll.201101198

Hydrogen Generation from Photocatalytic Silver | Zinc Oxide Nanowires: Towards Multifunctional Multisegmented Nanowire Devices

A. Wouter Maijenburg , Eddy J. B. Rodijk, Michiel G. Maas, Monica Enculescu, Dave H. A. Blank, and Johan E. ten Elshof * 
Supporting Information for

DOI: 10.1002/smll.201101198

\section{Hydrogen Generation from Photocatalytic Silver|Zinc Oxide Nanowires: Towards Multifunctional Multisegmented Nanowire Devices**}

A. Wouter Maijenburg, Eddy J.B. Rodijk, Michiel G. Maas, Monica Enculescu, Dave H.A. Blank and Johan E. ten Elshof

[*] Prof. J.E. ten Elshof, A.W. Maijenburg, E.J.B. Rodijk, Dr. M.G. Maas, Prof. D.H.A. Blank

MESA+ Institute for Nanotechnology, University of Twente

P.O. Box 217, 7500 AE Enschede (The Netherlands)

E-mail: j.e.tenelshof@utwente.nl

Dr. M. Enculescu

National Institute of Materials Physics

P.O. Box MG-7, 77125, Magurele-Bucharest (Romania)

\section{Experimental Details}

Nanowire Templates: Commercially available Nuclepore ${ }^{\circledR}$ (Whatman Inc.) polycarbonate track-etched (PCTE) membranes with a thickness of $6 \mu \mathrm{m}$, a pore diameter of $200 \mathrm{~nm}$ and a pore density of $\sim 3 \times 10^{8}$ pores $/ \mathrm{cm}^{2}$ were used as template for the formation of nanowires with lengths up to $6 \mu \mathrm{m}$.

To obtain templates for the synthesis of multifunctional multisegmented nanowires of more than $6 \mu \mathrm{m}$ length, polycarbonate foils with a thickness of $30 \mu \mathrm{m}$ were irradiated at the GSI in Darmstadt with swift heavy ions with fluences in the range $10^{4}-10^{9} \mathrm{ions} / \mathrm{cm}^{2}$. In order to obtain cylindrical pores the ion tracks were etched using a solution of $5 \mathrm{M} \mathrm{NaOH}$ containing $10 \%$ methanol at $50{ }^{\circ} \mathrm{C}$. In this way we prepared membranes containing pores with diameters ranging from $130 \mathrm{~nm}$ to $500 \mathrm{~nm}$. Further details can be found elsewhere. ${ }^{\text {[S1,S2] }}$

Nanowire Synthesis: Prior to electrodeposition, a gold layer with a thickness of $50 \mathrm{~nm}$ was sputtered on one side of the membrane. The gold coated side was then attached to a glass slide with double-sided tape and used as working electrode in a 3-electrode setup using a Bank Elektronik POS 73 potentiostat and an Autolab PGSTAT 128N potentiostat from Metrohm. As counter electrode a small piece of platinum mesh was used. The reference potential was set by a 3M KCl Ag/AgCl reference electrode (REF 321, Radio Analytical) or a Ag/AgCl reference electrode (Metrohm). Silver segments were deposited from an electrolyte solution containing 0.20 $\mathrm{M} \mathrm{AgNO}_{3}$ (99+\%, Acros) and 0.10 $\mathrm{M} \mathrm{H}_{3} \mathrm{BO}_{3}$ (99.99\%, Sigma-Aldrich). The $\mathrm{pH}$ was adjusted to 1.5 with nitric acid. Silver deposition was done potentiostatically at room temperature at $+0.10 \mathrm{~V}$ versus reference. Zinc oxide segments were deposited at $-1.00 \mathrm{~V}$ at $70^{\circ} \mathrm{C}$ from an aqueous electrolyte solution containing $0.10 \mathrm{M} \mathrm{Zn}\left(\mathrm{NO}_{3}\right)_{2} \cdot 6 \mathrm{H}_{2} \mathrm{O}(98 \%$, Sigma- 
Aldrich). Platinum segments were deposited at $-0.3 \mathrm{~V}$ from an aqueous solution containing $0.01 \mathrm{M} \mathrm{H}_{2} \mathrm{PtCl}_{6} \cdot 6 \mathrm{H}_{2} \mathrm{O}$ (Sigma-Aldrich). Gold segments were deposited using a saw-tooth potential ranging from $+0.97 \mathrm{~V}$ to $0 \mathrm{~V}$ and back to $+0.97 \mathrm{~V}$ at a scan rate of $0.01 \mathrm{~V} / \mathrm{s}$ from an aqueous solution containing $0.005 \mathrm{M} \mathrm{HAuCl}_{4} \cdot 3 \mathrm{H}_{2} \mathrm{O}$ (Sigma-Aldrich). Nickel segments were deposited at $-1.00 \mathrm{~V}$ from an aqueous electrolyte solution containing $0.23 \mathrm{M} \mathrm{NiSO}_{4} \cdot 6 \mathrm{H}_{2} \mathrm{O}$ (>99.0\%, Sigma-Aldrich) and $0.15 \mathrm{M} \mathrm{H}_{3} \mathrm{BO}_{3}$ (99.99\%, Sigma-Aldrich). After deposition, the PCTE membranes were dissolved in dichloromethane (Merck).

Characterization: The isolated nanowires were characterized using a Zeiss HR-LEO 1550 FEF Scanning Electron Microscope (SEM), before and after the photocatalytic experiments. EDX mapping was done using a NORAN EDS spectrometer equipped in the SEM. The $I-V$ characteristics were determined using a Karl Suss PM8 low leakage Manual Probe Station and a Keithley 4200 power source.

Photocatalytic experiments: Approximately $0.1 \mathrm{~g}$ of segmented nanowires were suspended in $50 \mathrm{~mL}$ of a $4: 1 \mathrm{vol} / \mathrm{vol}$ methanol/water mixture in a sealed quartz tube with a total volume of 72 mL. A Pd-based Kebaili KHS-100 hydrogen sensor, based on a palladium/nickel alloy which is highly selective for hydrogen, was placed in the plug and properly sealed. The hydrogen sensor was connected to a standard Wheatstone bridge. The voltage response was logged every second with a Peaktech multimeter connected to a computer. A UV-source of 60 $\mathrm{W}$ was used, at a distance of $10-15 \mathrm{~cm}$ from the sample. The experiments were performed in ambient atmosphere.

\section{References}

[S1] I. Enculescu, M. Sima, M. Enculescu, C. Ghica, M. Enache, R. Neumann, Journal of Optoelectronics and Advanced Materials 2007, 9, 1468.

[S2] M. Enculescu, Journal of Optoelectronics and Advanced Materials 2008, 10, 1501. 